\title{
SIMULATION OF TSUNAMI FORCE IN THE PRESENCE OF BEACHSIDE STRUCTURES
}

Tomoaki Nakamura, Nagoya University, tnakamura@nagoya-u.jp

Aya Yamashima, Furukawa Co., Ltd., ay.yamashita@furukawakk.co.jp

Norimi Mizutani, Nagoya University, mizutani@civil.nagoya-u.ac.jp

Yonghwan Cho, Nagoya University, yhcho@civil.nagoya-u.ac.jp

\section{INTRODUCTION}

The 2011 Tohoku earthquake tsunami caused a catastrophic disaster along the northeast coast of the Honshu Island, Japan. To deal with such massive tsunamis (identified as "level 2" tsunamis in Japan), the concept of disaster mitigation using multifaceted countermeasures is essential in addition to the construction of shore protection facilities for tsunamis at relatively high frequencies ("level 1" tsunamis). This study focused on one of such countermeasures, which involved beachside rigid structures. Such structures are expected to be effective for disaster mitigation because of the complementation of shore protection facilities by reducing tsunami force on rear buildings. To quantitatively evaluate the influence of beachside rigid structures on tsunami force, a three-dimensional (3-D) numerical analysis was performed using a 3-D coupled fluid-structure-sediment-seabed interaction model (FS3M; Nakamura and Mizutani, 2014).

\section{COMPUTATIONAL CONDITIONS}

The FS3M was applied to a 3-D computational domain of Fig. 1, which was modelled from hydraulic model experiments (scale: 1/25) performed at Oregon State University, USA (Bridges, 2011). A specimen (0.6×0.6× $0.4 \mathrm{~m}$ ) was set on the land, and macro-roughness cubic elements $a=0.6 \mathrm{~m}$ on a side were set at a distance of $d$ offshore from the specimen. A leading-elevation tsunami was generated so that water surface fluctuation at WG2 (see Fig. 1) matched with experimental data as possible. Under this wave condition, 58 patterns of numerical experiments including nine patterns in the hydraulic experiments (Bridges, 2011) were conducted changing the number and arrangement of the elements (Fig. 2).

\section{RESULTS AND DISCUSSION}

Figure 3 shows a comparison of inundation depth $\eta$ in front of the specimen and tsunami force $F$ on the specimen. From Fig. 3, it was observed that the numerical results were in good agreement with the experimental data except for seaward tsunami force (i.e., $F<0$ ) induced by return flow because a wave absorbing beach behind the specimen was not modelled due to the lack of its detail. From this result, it was found that the FS3M can predict water surface fluctuation, inundation

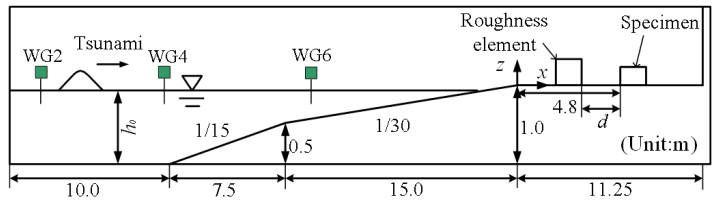

Figure 1 - Computational domain (cross-sectional view)

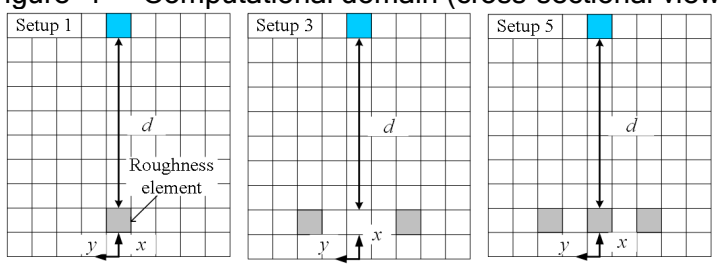

Figure 2 - Examples of the arrangement of the elements depth, and tsunami force with sufficient accuracy.

Figure 4 shows a ratio of the maximum tsunami force with the elements $F_{\max }$ to that for no elements $F_{\text {bmax }}$. From Fig. 4, it was found the numerical results had a similar trend with the hydraulic experiments. Moreover, it was suggested from $F_{\max } / F_{\text {bmax }}>1$ for $d / a=1$ and 4 of Setup 3 that determining the arrangement of rigid structures is essential to reduce tsunami force on rear buildings.

The maximum tsunami force was estimated to be $F_{0 \max }$ using the following drag force similar with the ASCE 7-16 standard from inundation depth $\eta_{0}$ and bottom flow velocity $u_{0}$ for no specimen:

$$
F_{0 \max }=0.5 \rho C_{D} a\left(\eta_{0} u_{0}^{2}\right)_{\text {max }}
$$

where $C_{D}$ is the drag coefficient $(=2.0$; common value for a square cylinder) and $\rho$ is the density of water. Figure 5 shows a comparison between $F_{\max }$ and $F_{0 \max }$. From Fig. 5 , it was found that the maximum tsunami force can be predicted reasonably well using Eq. (1) regardless of the number and arrangement of beachside rigid structures.

\section{ACKNOWLEDGMENTS}

The authors would like to thank Prof. Cox at Oregon State University, USA for providing experimental data.

\section{REFERENCES}

Bridges, K.-J. (2011): Influence of Macro-Roughness on Tsunami Runup and Forces, Master Thesis, Oregon State University, USA, $34 \mathrm{p}$.

Nakamura, T. and Mizutani, N. (2014): Development of fluid-sediment-seabed interaction model and its application, Proc., 34th ICCE, ASCE, sediment.85, E93.
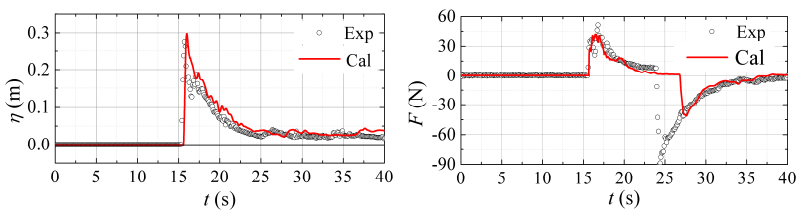

Figure 3 - Comparison of $\eta$ and $F$

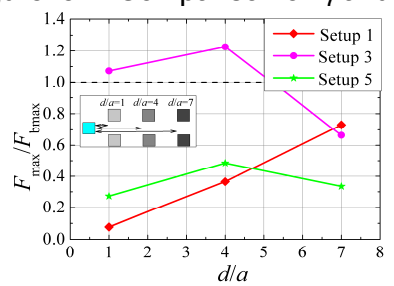

Figure 4 - Influence of the arrangement of the elements (see Fig. 2) on the maximum tsunami force

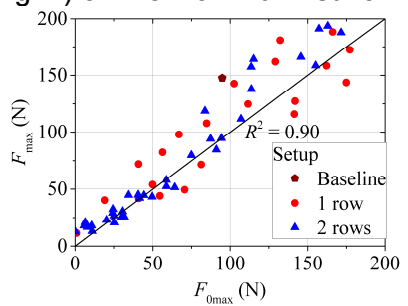

Figure 5 - Comparison of $F_{\max }$ and $F_{0 \max }$ 